es autor Aniceto Masferrer, La pervivencia del derecho foral valenciano tras los decretos de Nueva Planta, y, en tercer lugar, en torno al libro de Jesús Pérez López, El poder del principe en Roma. La Lex de Imperio Vespasiani.

Se cierra el correspondiente número con una crónica, escrita por Vicenç Subirats i Mulet, sobre la X Jornada de estudios locales de la villa de Bot, que tuvo lugar el 27 de octubre de 2007, y con una nota necrológica de Joan Miquel, catedrático de Derecho romano que lo fue de las Universidades de La Laguna, Barcelona y Pompeu Fabra, escrita por algunos de sus discípulos (tuvo muchos más), en concreto Encarnació Ricart i Martí, José Luis Linares Pineda, Victoria Sansón Rodríguez y Carmen Tort-Martorell i Llabrés.

Manuel J. Peláez Universidad de Málaga

Revista di diritto dell'intengrazione e unificazione del diritto in Europa e in America Latina, 25 (Roma, 2008), 290 págs.

\title{
DE ÍNDICE:
}

Sistema giuridico latinoamericano: José Carlos Moreira Alves, Os 150 anos da Consolidaçao das Leis Civis de Teixeira de Freitas: reflexões sobre a sua importancia na formaçao do direito brasileiro (pp. 3-9); Víctor J. Castellanos, La influencia del derecho francés sobre el derecho dominicano (pp. 11-38); Fábio Siebeneichler De Andrade, Harmonização e codificação do direito civil no Mercosul: Quo vadis?, (pp. 39-52); Gina María Acuña Solorzano, Los interdictos populares como instrumento de tutela a las res in usu publico en el derecho romano y su influencia en las codificaciones latinoamericanas. Con atención a la tutela del ambiente (pp. 53-79).

Lavoro autonomo e diritto del lavoro: quali frontiere?: Giancarlo Perone, L'implicazione della persona nel lavoro autonomo (pp. 83-111); Augusto Conti, Lavoro autonomo: esperienza e problemi nei paesi del Patto Andino (pp. 113-128); Oscar Hernández Álvarez, Esperienze e problemi in Venezuela e in altri paesi latini caraibici (pp. 129-138); Márcio Túlio Viana, Lavoro informale in Brasile: risultati di un'indagine sul campo (pp.139-148); José Manuel Gómez Muñoz, El estatuto del trabajador autónomo en España: ¿una legislación fraude? (pp. 149-165); Alessandro Anastasi, Esperienze e problemi nei paesi dell'Europa centro-orientale (pp. 167-216); Antonella D'Andrea, Il lavoro non subordinato nell'ordinamento internazionale: punti critici della Raccomandazione n. 198/2006 dell'I.L.O. (pp. 217-222).

RED.

Revue Internationale des Droits de l'Antiquité, 55 (2008) 3, 570 págs.

Del índice:

Droits de l'orient ancien: B. Geva, The monetary legal theory under the talmud (pp. 13-38); R. Westbrook, The origin of Laesio Enormis (pp. 39-52).

Droit romain: $\mathrm{H}$. Ankum, La relation entre la litis contestatio et la sentence du juge dans l'exceptio rei iudicatae vel in iudicium deductae de la procédure formulaire du droit 